\title{
Lower-Body Positive Pressure Treadmill Training for Pediatric Gait Disorders: A Scoping Review
}

\author{
Yosra Cherni ${ }^{1,2, *}$, Léandre Gagné-Pelletier ${ }^{1,2}$, Laurent Bouyer ${ }^{1,2}\left(\mathbb{C}\right.$ and Catherine Mercier ${ }^{1,2} \mathbb{C}$ \\ 1 Department of Rehabilitation, Laval University, Québec, QC G1V 0A6, Canada; \\ leandre.gagne-pelletier.ciussscn@ssss.gouv.qc.ca (L.G.-P.); Laurent.Bouyer@rea.ulaval.ca (L.B.); \\ Catherine.Mercier@rea.ulaval.ca (C.M.) \\ 2 Center for Interdisciplinary Research in Rehabilitation and Social Integration, Québec, QC G1M 2S8, Canada \\ * Correspondence: yosra.cherni.1@ulaval.ca
}

Citation: Cherni, Y.;

Gagné-Pelletier, L.; Bouyer, L.;

Mercier, C. Lower-Body Positive

Pressure Treadmill Training for

Pediatric Gait Disorders: A Scoping

Review. Appl. Sci. 2022, 12, 323.

https://doi.org/

10.3390/app12010323

Academic Editor: René Schwesig

Received: 30 November 2021

Accepted: 28 December 2021

Published: 29 December 2021

Publisher's Note: MDPI stays neutral with regard to jurisdictional claims in published maps and institutional affiliations.

Copyright: (C) 2021 by the authors. Licensee MDPI, Basel, Switzerland. This article is an open access article distributed under the terms and conditions of the Creative Commons Attribution (CC BY) license (https:// creativecommons.org/licenses/by/ $4.0 /)$.

\begin{abstract}
The purpose of this scoping review was to examine the literature on the use of antigravity treadmills and its effects on lower-limb motor functions in children and adolescents with locomotor impairments. Method: Four databases (MEDLINE, CINAHL, Embase, Web of Science) were searched for articles from inception to August 2021. Inclusion criteria were: (1) experimental or quasi-experimental studies using anti-gravity training as the primary intervention; (2) studies conducted in pediatric participants; (3) articles reporting outcomes related to lower-limb functions; and (4) studies published in French or English. Results: Fifteen articles were included in the review. Studies included children and adolescents aged 4-18 years with locomotor impairments. Intervention duration ranged from 2 to 12 weeks, with 2-5 sessions per week. Included studies reported that antigravity training induces improvements in muscle strength, balance, spatiotemporal gait parameters, and walking endurance in children with locomotor impairments. Conclusion: This review provides relevant information about interventions, outcomes and limits associated with anti-gravity training in pediatrics. Overall, anti-gravity treadmill training could be viewed as a valuable training modality, specifically for children with cerebral palsy. However, a more precise and comprehensive description of anti-gravity training protocols would be useful.
\end{abstract}

Keywords: pediatric; gait; rehabilitation; anti-gravity; treadmill

\section{Introduction}

Locomotor impairments in children can result from different causes, including cerebral palsy, traumatic brain injury, orthopedic surgery or musculoskeletal pathology. These impairments manifest themselves in various ways, such as a decrease in walking speed (due to a reduced step length and/or cadence), increase in double-support duration, reduced lower-limb range of motion and poor endurance [1-3]. They can have a detrimental effect on walking capacity and accordingly affect children's social participation and quality of life $[4,5]$. A priority of physical therapy interventions is therefore to improve gait quality, speed, independence, and efficiency.

The development of new devices and apparatuses can support efforts made by therapists to optimize rehabilitation of gait function. For instance, treadmill training is a specific locomotor training modality that promotes massive repetition of the gait movement. Zwicker and Mayson [6] conducted an umbrella review on the effectiveness of treadmill training in children with locomotor impairments. They concluded that treadmill training is effective overall, and no negative outcomes were reported. Complementary technologies, such as partial body-weight support (BWS) systems, can be used during treadmill training to ensure a safe environment that makes locomotor training easier for children with severe locomotor disorders [7]. BWS systems can also potentially reduce ground reaction forces (i.e., average and/or peak vertical ground reaction forces), thereby 
allowing the intensity of training needed for rehabilitation while protecting the lower-limb joints [8,9]. Despite their usefulness for gait rehabilitation, it is important to underline the discomfort caused by lifting forces provided by the harnesses straps, which can impact the duration of training sessions and hinder a participant's compliance with the training protocol. To address this issue, some innovative BWS treadmill training systems employing lower-body positive-pressure support have been developed, of which the most widely distributed is the anti-gravity treadmill (AlterG ${ }^{\circledR}$ ) [10]. These systems rely on differential air-pressure technology, using a chamber on a treadmill that allows the lower body to be supported by air pressure [11]. It must be noted, however, that this suspension system, despite its name, does not remove gravity per se; overall body weight is reduced, but the actual weight of the lower limbs remains the same. The term 'anti-gravity' will, however, be used in this review for the sake of simplicity and to differentiate air-pressure bodyweight-supported systems from classical body-weight-supported systems. The anti-gravity treadmill allows users to run or walk while removing up to $80 \%$ of their body weight without using a body-suspension harness system, which can make rehabilitation easier and occur earlier. Anti-gravity treadmill training is increasingly used in adults after knee surgery and lower-limb sport injuries to reduce ground reaction forces during walking and running to facilitate postoperative rehabilitation $[10,12,13]$. Despite the promising results concerning this technology, it still requires further investigation to optimize technological development, support routine clinical use and verify its effectiveness in children with locomotor impairments. The current evidence concerning its clinical use and effectiveness in the pediatric population with locomotor impairments is limited, and no synthesis has been produced yet, which could play an important role in guiding future research. Therefore, the aim of the present study was to perform a scoping review of the literature related to the use of anti-gravity treadmills and to identify profiles of pediatric populations with specific lower-limb motor-function deficits for which effects have been reported.

\section{Materials and Methods}

\subsection{Data Source and Literature Source}

A science librarian was consulted for the initial development of the search protocol. Studies were identified by searching Medline, Embase, CINHAL and Web of Science from inception to August 2021. The search strategy was based on three main concepts: antigravity treadmill training, lower-limb motor functions and pediatric population. More details concerning search strategy and the key words used are reported in Table S1 as a supplementary material. The current scoping review follows the guidelines of the Preferred Reporting Items for Systematic reviews and Meta-Analyses extension for Scoping Reviews (PRISMA-ScR) [14,15] and was registered with the OSF Registries on 3 September 2021 (osf.io/8k6em). The study did not require ethical approval.

\subsection{Eligibility Criteria}

The included studies met the following inclusion criteria: (1) experimental studies, such as randomized controlled trials, before/after studies, multiple case studies, controlled case studies and single case studies; (2) conducted on a majority of pediatric participants $\leq 19$ years; (3) specifically used anti-gravity training as a primary intervention method for $>1$ session; (4) articles reporting at least one variable related to lower-limb function and (5) studies published in French or English.

Articles were excluded if they: (1) focused on adult populations; (2) focused solely on outcomes other than the function of the lower limbs; and (3) were not original research, such as letters to editor, conference abstracts and commentaries.

\subsection{Study Screening}

Titles and abstracts of the identified studies were screened independently by two of the authors (Y.C. and L.P.) to identify those that potentially met the inclusion criteria. A full review of the manuscripts was then performed independently by the same authors. 
In the case of any unresolvable disagreement related to the eligibility of studies, a third author (C.M.) was available.

\subsection{Quality Assessment}

Subsequently, Y.C. and L.P. independently rated the overall quality of each article included in this study, using the PEDro scale, which ranges from 0 to 10 [16]. This scale allows for identification of trials that are likely to be valid and have sufficient statistical information to guide clinical decision making. Each trial report was given a total PEDro score. A calibration meeting was initially held with five articles to ensure a clear understanding of each criterion and thus a standardization and reliability of assessments. A second meeting was held to discuss the criteria for each included article until a consensus was reached concerning a score. In the case of any unresolvable disagreement, a third author (C.M.) performed the assessment to reach consensus.

\subsection{Outcome Variables}

One author (Y.C.) extracted data, including study design and therefore the level of evidence (based on Pedro scale), population characteristics, intervention (and comparison with a control group), intervention parameters, outcomes and results. Outcomes were classified according to the International Classification of Functioning, Disability and Health (body structure/function (e.g., muscle power, contractures, spasticity) and activity domains (e.g., mobility)) [17]. Body structures are defined as anatomical body parts, and body functions are the physiological processes of the body and activity for the execution of a specific task or action [17].

\section{Results}

The initial search identified 678 potentially relevant articles. After duplicate removal $(n=111)$, two reviewers independently evaluated 567 articles based on their titles and abstracts. In the title/abstract reading stage, 26 articles were determined, by consensus, to meet the predetermined criteria, which qualified them for the full-text reading stage. The implementation of this last procedure resulted in the selection of 15 articles that were classified as eligible for this review (Figure 1).

\subsection{Design and Quality of the Studies}

Tables 1 and 2 summarize the research design and PEDro rating score. Regarding the study design, we identified six randomized controlled trials (RCT), four multiple case studies, two before-and-after studies, one case study, one control case study and one nonequivalent control-group study. The methodological quality of the included studies ranged from 1 to 8 out of 10 , with a median score of 2 . Four studies [11,18-20] were of high quality (PEDro score $\geq 6$ ), while the others were of low quality (PEDro score $\leq 3$ ).

\subsection{Participant Characteristics}

Fourteen of the fifteen studies focused on a pediatric population with cerebral palsy, and one study was interested in children with hemophilic knee arthritis. The sample size in the included studies ranged from 1 to 30 participants (total of 185 across all studies), and participant demographics varied considerably (see Table 1). For children with $\mathrm{CP}$, the classification of participants' movement-disorder severity based on the Gross Motor Function Classification System (GMFCS) varied between studies from levels I to IV (at level I, children walk, run and jump, but speed, balance and coordination are limited; at level IV, children use a wheelchair for propulsion).

\subsection{Training Protocols}

Protocol descriptions are presented in Table 3. In three studies, anti-gravity treadmill training was combined with conventional therapy (e.g., stretching and strengthening exercise, physical therapy or occupational therapy focused on walking capacity) $[11,18,19]$. 
In the other studies, participants performed training with the anti-gravity treadmill only. Ten studies compared the effect of anti-gravity training to a control intervention, such as conventional physical therapy $[11,18,19,21]$, occupational therapy focused on walking capacity [22-26] and robotic and BWS treadmill training [20]. The training protocols presented across studies varied in intensity and duration (see Table 2). Training was typically conducted with a frequency of two or five times a week in sessions lasting 20-45 min each, for a total intervention duration ranging from 2 to 12 weeks. The settings of the anti-gravity treadmill were similar across the different studies: body weight support was initially set at 30-50\%, then decreased progressively; gait speed was initially set at $0.7-1.5 \mathrm{~km} / \mathrm{h}$, then gradually increased. However, none of the studies reported individual data to describe how settings were progressed.

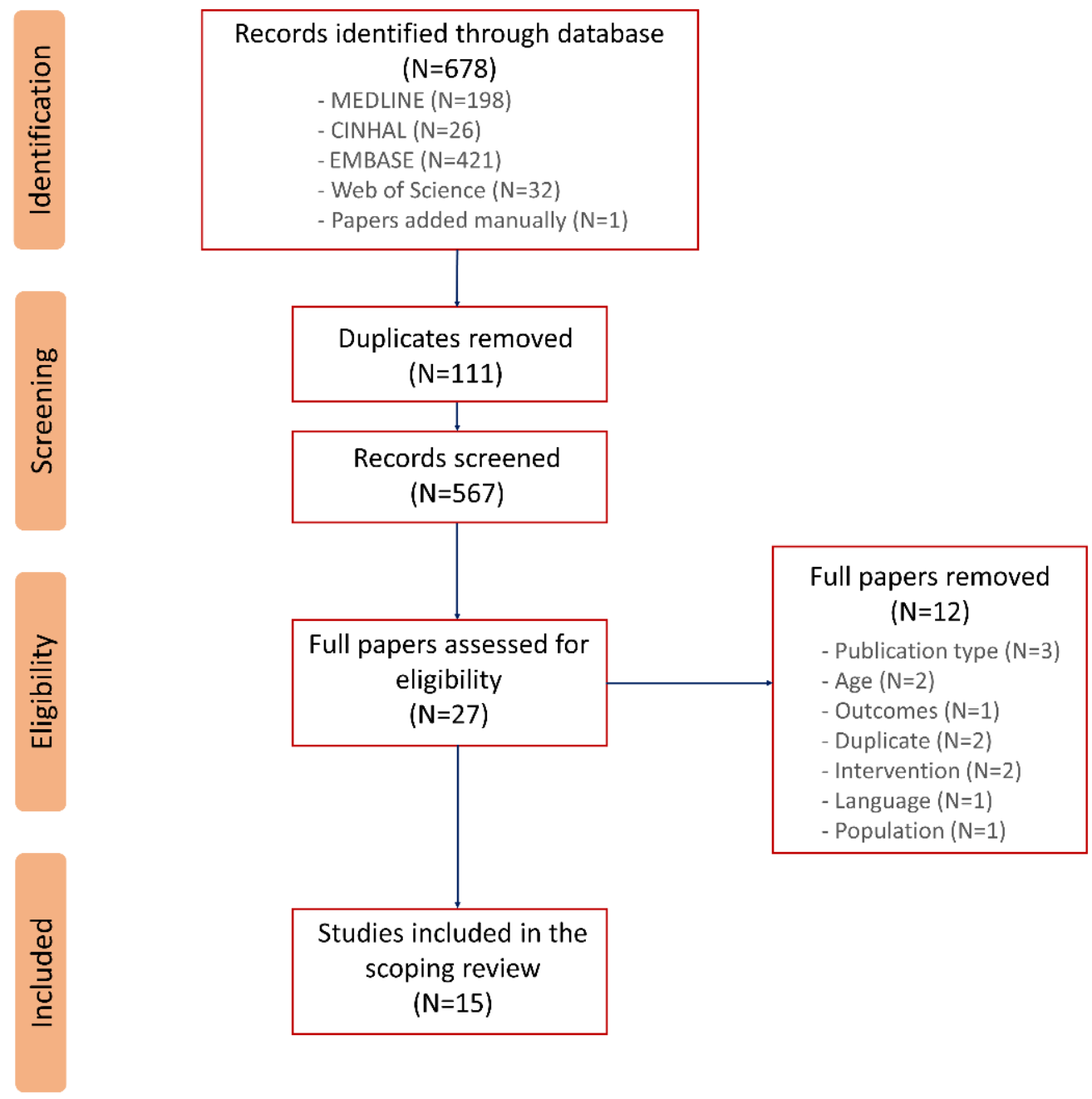

Figure 1. Prisma flow chart of the selection process.

3.4. Effect of Anti-Gravity Treadmill Training on Muscle Strength, Spasticity and Gross Motor Function

Some studies investigated the effect of anti-gravity training on lower-limb muscle strength $[18,27,28]$ and spasticity [26], as well as gross motor function [20]. Few studies assessed muscle strength in isometric $[27,28]$ or concentric mode [18] or the rate of force development [28]. They highlighted an increase in ankle and knee isometric muscle strength, as well as in the rate of force development after anti-gravity training. Regarding spasticity, Noroozi et al. [26] reported a decrease in intrinsic and reflex stiffness following anti-gravity training. The changes were greater than those observed in the control group. Finally, Aras et al. [20] reported a significant improvement in the gross motor function measure (GMFM-66) after the different training modalities (AlterG, BWS and Lokomat) 
in both GMFM-D (standing section) and GMFM-E (walking-running section). However, there was no statistically significant difference between the groups in terms of GFMF-D and GMFM-E.

\subsection{Effect of Anti-Gravity Treadmill Training on Balance}

Several studies explored the effects of anti-gravity training on balance control in children with locomotor impairments [11,18,19,21-25,27,29-31]. The findings of those studies are summarized in Table 2. Balance assessments included center-of-pressure (CoP) measurements (i.e., CoP sway, CoP velocity, etc.) during static (standing) [21,29] and dynamic balance assessment using center-of-mass and center-of-pressure displacements $[18,19,23,25]$, as well as clinical tests, such as the BESTest, the Berg Balance Score (BBS) or Timed Up and Go (TUG) test [22,24,25,27,30,31]. All included studies reported improvements in balance following anti-gravity training. Moreover, six studies highlighted a greater improvement in balance compared to conventional therapies [11,18,19,21-23].

\subsection{Effect of Anti-Gravity Treadmill Training on Gait Parameters}

Gait-related outcomes were commonly measured during over-ground walking and included spatiotemporal parameters (i.e., walking speed, stride length, step length, cadence, etc.) and endurance. Some studies reported a significant effect of anti-gravity training, mainly on gait speed $[11,20,22,24,25,27,28,31]$, step length $[11,20,28]$, cadence $[11,20]$ and walking endurance [20,24,25,31]. Regarding walking endurance, Aras et al. [20] observed a significant improvement after all three training modalities (AlterG, BWS and robotic training). However, there was no statistically significant difference between the groups.

Table 1. Results of methodological quality of articles using the PEDro score.

\begin{tabular}{cccccccccccccc}
\hline Studies & Study Design & $\mathbf{1}$ & $\mathbf{2}$ & $\mathbf{3}$ & $\mathbf{4}$ & $\mathbf{5}$ & $\mathbf{6}$ & $\mathbf{7}$ & $\mathbf{8}$ & $\mathbf{9}$ & $\mathbf{1 0}$ & $\mathbf{1 1}$ & Total (/10) \\
\hline Kurz et al. [16] & Before/After & 0 & 0 & 0 & 0 & 0 & 0 & 0 & 1 & 1 & 0 & 1 & 3 (low) \\
Emara [21] & RCT & 1 & 1 & 1 & 1 & 0 & 0 & 0 & 1 & 1 & 1 & 1 & 7 (high) \\
Emara [22] & RCT & 1 & 1 & 1 & 1 & 0 & 0 & 0 & 1 & 1 & 1 & 1 & 7 (high) \\
Birgani et al. [26] & Case study & 0 & 0 & 0 & 0 & 0 & 0 & 0 & 1 & 1 & 0 & 0 & 2 (low) \\
El-Shamy [11] & RCT & 1 & 1 & 1 & 1 & 0 & 0 & 1 & 1 & 1 & 1 & 1 & 8 (high) \\
Rasooli et al. [27] & Multiple case studies & 0 & 0 & 0 & 0 & 0 & 0 & 0 & 1 & 1 & 0 & 0 & 2 (low) \\
Lotfian et al. [23] & Multiple case studies & 0 & 0 & 0 & 0 & 0 & 0 & 0 & 0 & 0 & 0 & 1 & 1 (low) \\
Azizi et al. [28] & RCT & 0 & 1 & 0 & 0 & 0 & 0 & 0 & 1 & 1 & 0 & 0 & 3 (low) \\
Azizi et al. [29] & Multiple case studies & 0 & 0 & 0 & 0 & 0 & 0 & 0 & 1 & 1 & 0 & 0 & 2 (low) \\
Azizi et al. [30] & Multiple case studies & 0 & 0 & 0 & 0 & 0 & 0 & 0 & 1 & 1 & 0 & 0 & 2 (low) \\
Dadashi et al. [31] & Controlled cases study & 0 & 0 & 0 & 0 & 0 & 0 & 0 & 1 & 1 & 0 & 0 & 2 (low) \\
Azizi et al. [15] & RCT & 0 & 1 & 0 & 1 & 0 & 0 & 0 & 0 & 0 & 1 & 1 & 4 (low) \\
Lotfian et al. [32] & Before/After & 0 & 0 & 0 & 0 & 0 & 0 & 0 & 0 & 0 & 0 & 1 & 1 (low) \\
Aras et al. [25] & RCT & 1 & 1 & 1 & 1 & 0 & 0 & 0 & 1 & 1 & 1 & 1 & 7 (high) \\
Noroozi et al. [24] & NECG & 0 & 0 & 0 & 0 & 0 & 0 & 0 & 0 & 0 & 0 & 1 & 1 (low) \\
\hline
\end{tabular}

NOTE. RCT: randomized controlled trial; NECG: nonequivalent control-group. The PEDro scale consists of 11 items: Item 1. eligibility criteria were specified. Item 2. subjects were randomly allocated to groups. Item 3. allocation was concealed. Item 4 . The groups were similar at baseline regarding the most important prognostic indicators. Items 5-7. There was blinding of all subjects, therapists and assessors. Item 8 . Measures of at least one key outcome were obtained from more than $85 \%$ of the subjects initially allocated to groups. Item 9. All subjects for whom outcome measures were available received the treatment or control condition as allocated or, where this was not the case, data for at least one key outcome were analyzed by "intention-to-treat". Item 10. The results of between-group statistical comparisons are reported for at least one key outcome. Item 11 The study provides both point measures and measures of variability for at least one key outcome. Each item is scored as a "yes" or "no", worth 1 or 0 points, respectively. The total score expressed on a 10-point scale. The first item is not included in the sum of the total score of the PEDro scale. 
Table 2. Summary of participant characteristics and outcomes.

\begin{tabular}{|c|c|c|c|c|c|c|c|}
\hline \multirow[t]{2}{*}{ Study } & \multicolumn{2}{|c|}{ Participant Characteristics } & \multicolumn{2}{|c|}{ Intervention } & \multirow[t]{2}{*}{ Outcomes of Interest } & \multirow[t]{2}{*}{ ICF Domains } & \multirow[t]{2}{*}{ Results } \\
\hline & $\begin{array}{l}\text { Experimental } \\
\text { Group }\end{array}$ & Control Group & Anti-Gravity Training & $\begin{array}{l}\text { Comparator } \\
\text { Training }\end{array}$ & & & \\
\hline \multirow{2}{*}{$\begin{array}{l}\text { Kruz } \\
\text { et al. [27] }\end{array}$} & $\begin{array}{l}9 \text { children } \\
\text { with CP }\end{array}$ & - & \multirow{2}{*}{$\begin{array}{l}\text { Anti-gravity training } \\
\text { (2 participants continued } \\
\text { conventional therapy) }\end{array}$} & \multirow[t]{2}{*}{-} & \multirow{2}{*}{$\begin{array}{l}\text { Isometric muscle strength; } \\
\text { spatiotemporal parameters; } \\
\text { balance (BESTest) }\end{array}$} & \multirow[t]{2}{*}{$\begin{array}{l}\text { Body function } \\
\text { and activity }\end{array}$} & \multirow{2}{*}{$\begin{array}{l}\text { A significant improvement in the overall strength of the } \\
\text { lower extremity, walking speed, time spent in the double } \\
\text { support and BESTest scores after anti-gravity training. }\end{array}$} \\
\hline & \multicolumn{2}{|c|}{ (age $=8$ to 18 yrs; GMFCS II-V) } & & & & & \\
\hline \multirow{2}{*}{$\begin{array}{l}\text { Emara } \\
\text { et al. }[18]\end{array}$} & $\begin{array}{l}15 \text { children with } \\
\text { hemophilic } \\
\text { knee arthritis }\end{array}$ & $\begin{array}{l}15 \text { children with } \\
\text { hemophilic } \\
\text { knee arthritis }\end{array}$ & \multirow{2}{*}{$\begin{array}{l}\text { Anti-gravity training } \\
\quad+\text { stretching and } \\
\text { strengthening exercise }\end{array}$} & \multirow{2}{*}{$\begin{array}{l}\text { Stretching and } \\
\text { strengthening } \\
\text { exercises }\end{array}$} & \multirow{2}{*}{$\begin{array}{l}\text { Concentric muscle strength } \\
\text { (hamstrings and } \\
\text { quadriceps); balance }\end{array}$} & \multirow[t]{2}{*}{$\begin{array}{l}\text { Body function } \\
\text { and activity }\end{array}$} & \multirow{2}{*}{$\begin{array}{l}\text { Peak torque of the quadriceps and peak torque of the } \\
\text { hamstring increased in the control and anti-gravity } \\
\text { group. Both groups demonstrated a significant increase } \\
\text { in balance. Greater improvements were in favor of the } \\
\text { anti-gravity group. }\end{array}$} \\
\hline & \multicolumn{2}{|c|}{ Age $=8$ to $11 \mathrm{yrs}$} & & & & & \\
\hline \multirow{2}{*}{$\begin{array}{l}\text { Emara } \\
\text { et al. }[19]\end{array}$} & $\begin{array}{l}15 \text { spastic } \\
\text { diplegic } C P\end{array}$ & $\begin{array}{l}15 \text { spastic } \\
\text { diplegic } \mathrm{CP}\end{array}$ & \multirow{2}{*}{$\begin{array}{l}\text { Anti-gravity training + the } \\
\text { same exercise program } \\
\text { given to control group }\end{array}$} & \multirow{2}{*}{$\begin{array}{l}\text { Personalized } \\
\text { therapeutic } \\
\text { exercise program }\end{array}$} & \multirow{2}{*}{$\begin{array}{l}\text { Dynamic postural control (AP } \\
\text { stability and M-L stability; } \\
\text { overall stability/index) }\end{array}$} & \multirow[t]{2}{*}{ Activity } & \multirow{2}{*}{$\begin{array}{l}\text { A greater stability index was observed after anti-gravity } \\
\text { training compared with the control group. }\end{array}$} \\
\hline & Age $=$ & $8 \mathrm{yrs}$ & & & & & \\
\hline $\begin{array}{l}\text { Birgani } \\
\text { et al. [29] }\end{array}$ & $\begin{array}{l}1 \text { hemiplegic } \\
\text { CP child }\end{array}$ & - & Anti-gravity training & - & $\begin{array}{l}\text { Balance and postural stability } \\
\text { based on the COP }\end{array}$ & Activity & The surface of $\mathrm{COP}$ signal decreased after training. \\
\hline \multirow{2}{*}{$\begin{array}{l}\text { El-Shamy } \\
{[11]}\end{array}$} & $\begin{array}{l}15 \text { spastic } \\
\text { diplegic } C P\end{array}$ & $\begin{array}{l}15 \text { spastic } \\
\text { diplegic } C P\end{array}$ & \multirow[t]{2}{*}{$\begin{array}{l}\text { Anti-gravity and } \\
\text { conventional therapy }\end{array}$} & \multirow{2}{*}{$\begin{array}{c}\text { Conventional } \\
\text { physical } \\
\text { therapy program }\end{array}$} & \multirow{2}{*}{$\begin{array}{l}\text { Gait spatiotemporal } \\
\text { parameters, postural stability, } \\
\text { fall risk }\end{array}$} & Activity & $\begin{array}{l}\text { Anti-gravity group exhibited greater improvements in } \\
\text { terms of spatiotemporal parameters, stability index and }\end{array}$ \\
\hline & Age $=8$ to 12 & ;GMFCS I-II & & & & & fall risk compared to the control group. \\
\hline $\begin{array}{l}\text { Rasooli } \\
\text { et al. [21] }\end{array}$ & $\begin{array}{l}3 \text { children with } \\
\text { spastic } \\
\text { hemiplegic } \mathrm{CP}\end{array}$ & $\begin{array}{l}1 \text { child with } \\
\text { spastic } \\
\text { hemiplegic CP }\end{array}$ & Anti-gravity training & $\begin{array}{l}\text { Over-ground } \\
\text { gait training }\end{array}$ & $\begin{array}{l}\text { Postural } \\
\text { stability (posturography) }\end{array}$ & Activity & $\begin{array}{l}\text { The results of the posturography evaluations showed a } \\
\text { consistent improvement in postural stability in }\end{array}$ \\
\hline & Age $=6$ to 12 & GMFCS I-III & & & & & \\
\hline Lotfian & $\begin{array}{l}4 \text { children } \\
\text { with } C P\end{array}$ & - & Ant-araity trining & - & Isometric strength, RFD, & Body function & $\begin{array}{l}\text { Ankle and knee isometric strength and RFD isokinetic } \\
\text { strength increased after anti-gravity training. Ankle }\end{array}$ \\
\hline et al. [28] & $\begin{array}{l}\text { Age }=c \\
\text { GMF }\end{array}$ & $\begin{array}{ll}13 \mathrm{yrs}, \\
\mathrm{II}-\mathrm{III}\end{array}$ & Aru-graviny tramming & & gait parameters & and activity & $\begin{array}{l}\text { AROM increased with training. Walking speed and step } \\
\text { width and length increased after anti-gravity training. }\end{array}$ \\
\hline Azizi & $\begin{array}{c}3 \text { children with } \\
\text { spastic hemiplegic }\end{array}$ & $\begin{array}{l}1 \text { child with spas- } \\
\text { tic hemiplegic }\end{array}$ & Anti-gravity training & OT focused on & Walking speed (10MWT) and & Activity & $\begin{array}{l}\text { Walking speed increased by between } 26 \text { and } 82 \% \text { after } \\
\text { anti-gravity training, whereas it was limited to } 35 \% \text { for }\end{array}$ \\
\hline & Age $=4$ & $12 \mathrm{yrs}$ & & Walking capacity & dynamic balance (IUG) & & $\begin{array}{l}\text { relatively small. } \\
\text { relin } 10 G \text { was } \\
\end{array}$ \\
\hline Azizi & $\begin{array}{l}3 \text { children } \\
\text { with CP }\end{array}$ & - & Anti-gravity training & - & $\begin{array}{l}\text { Walking speed (10MWT), } \\
\text { dynamic balance (TUG) }\end{array}$ & Activity & $\begin{array}{l}\text { All cases increased their walking speed, decreased the } \\
\text { time recorded in TUG and increased the distance during }\end{array}$ \\
\hline & Age $=\varsigma$ & $12 \mathrm{yrs}$ & & & endurance (6MWT) & & 6MWT after anti-gravity training. \\
\hline Azizi et al. & $\begin{array}{l}3 \text { children } \\
\text { with } C P\end{array}$ & - & Anti-gravity training & - & Balance using the BBS & Activity & The time in TUG decreased by up to $30 \%$ and the Berg \\
\hline & Age $=c$ & $12 \mathrm{yrs}$ & & & and TUG & & anti-gravity training. \\
\hline Dadashi & $\begin{array}{l}2 \text { children with } \\
\text { hemiplegic } \mathrm{CP}\end{array}$ & $\begin{array}{l}2 \text { children with } \\
\text { hemiplegic } C P\end{array}$ & Anti-gravity training & OT focused on & $\begin{array}{l}\text { Dynamic balance } \\
\text { (center-of-mass and }\end{array}$ & Activity & $\begin{array}{l}\text { Dynamic balance improved after anti-gravity training. } \\
\text { The changes were greater after anti-gravity training }\end{array}$ \\
\hline et al. [23] & Age $=4$ & $14 \mathrm{yrs}$ & & & displacements) & & oared to control traini \\
\hline Azizi & $\begin{array}{l}9 \text { children } \\
\text { with CP }\end{array}$ & $\begin{array}{l}5 \text { children } \\
\text { with CP }\end{array}$ & Anti-gravity training & OT focused on & $\begin{array}{l}\text { Walking speed (10MWT), } \\
\text { dynamic balance (TUG), }\end{array}$ & Activity & $\begin{array}{l}\text { Improvements in walking speed and endurance, } \\
\text { measured by 10MWT and 6MWT, were statistically }\end{array}$ \\
\hline & Age $=4$ & $15 \mathrm{yrs}$ & & & endurance $(6 \mathrm{MWT}$ & & control group. \\
\hline $\begin{array}{l}\text { Lotfian } \\
\text { et al. [25] }\end{array}$ & $\begin{array}{l}7 \text { children } \\
\text { with CP }\end{array}$ & $\begin{array}{l}4 \text { children } \\
\text { with CP }\end{array}$ & Anti-gravity training & $\begin{array}{l}\text { OT focused on } \\
\text { walking capacity }\end{array}$ & $\begin{array}{l}\text { Gait spatiotemporal } \\
\text { parameters, dynamic balance } \\
\text { (COP and COM displacement), } \\
\text { clinical measures (10MWT, }\end{array}$ & Activity & $\begin{array}{l}\text { Walking speed, cadence and single-support time } \\
\text { increased by } 98 \%, 10 \% \text { and } 65 \% \text {, respectively. Clinical } \\
\text { measures increased by } 26 \%(10 \mathrm{MWT}), 18 \% \text { (TUG) and } \\
20 \% \text { ( } 6 \mathrm{MWT} \text { ) after anti-gravity training. Dynamic } \\
\text { balance improved after anti-gravity training. All the }\end{array}$ \\
\hline & GMF & $=\mathrm{I}-\mathrm{II}$ & & & IUG, 6MWI) & & $\begin{array}{l}\text { changes were greater to control training. } \\
\text { compared training }\end{array}$ \\
\hline $\begin{array}{c}\text { Aras } \\
\text { et al. [20] }\end{array}$ & $\begin{array}{l}10 \text { children } \\
\text { with CP } \\
\text { (one withdrawn) }\end{array}$ & $\begin{array}{l}10 \text { children with } \\
\text { CP in robotic } \\
\text { group and } \\
10 \text { children with } \\
\text { CP in BWS } \\
\text { training group }\end{array}$ & Anti-gravity training & $\begin{array}{l}\text { A group } \\
\text { allocated for } \\
\text { BWS treadmill } \\
\text { training and a } \\
\text { group allocated }\end{array}$ & $\begin{array}{c}\text { Gait spatiotemporal } \\
\text { parameters, walking } \\
\text { endurance (6MWT), } \\
\text { GMFM-66 }\end{array}$ & Activity & $\begin{array}{l}\text { Walking speed increased in the three groups but did not } \\
\text { reach statistical significance. After anti-gravity training, } \\
\text { the increase in cadence, stride length, and stride time } \\
\text { were statistically significant. The decrease in the } \\
\text { double-support phase was statistically significant in the }\end{array}$ \\
\hline & $\begin{array}{c}\mathrm{Age}=6 \\
\text { GMF }\end{array}$ & $\begin{array}{l}14 \text { yrs; } \\
\text { II-III }\end{array}$ & & $\begin{array}{l}\text { for } \\
\text { robotic training }\end{array}$ & & & $\begin{array}{l}\text { ant1-gravity and robotic groups. GFMF-D, GMFM-E and } \\
6 \mathrm{MWT} \text { increased similarly in all the groups. }\end{array}$ \\
\hline $\begin{array}{l}\text { Noroozi } \\
\text { et al. [33] }\end{array}$ & $\begin{array}{l}9 \text { children with } \\
\text { hemiplegic CP } \\
\text { (1 withdrawn) }\end{array}$ & $\begin{array}{l}9 \text { children with } \\
\text { hemiplegic CP } \\
\text { (1 withdrawn) }\end{array}$ & Anti-gravity training & $\begin{array}{l}\text { OT focused on } \\
\text { walking capacity }\end{array}$ & $\begin{array}{l}\text { Ankle dorsiflexion spasticity } \\
\text { by assessment of reflex } \\
\text { stiffness gain and intrinsic }\end{array}$ & Body function & $\begin{array}{l}\text { Intrinsic stiffness gain and reflex stiffness gain } \\
\text { parameters decreased substantially following } \\
\text { anti-gravity training. The changes were greater than }\end{array}$ \\
\hline & Age $=4$ & $14 \mathrm{yrs}$ & & & & & 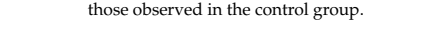 \\
\hline
\end{tabular}

Abbreviations: CP: cerebral palsy, GMFCS: Gross Motor Function Classification System, OT: occupational therapy, BESTest: balance evaluation systems test, 10MWT: $10 \mathrm{~m}$ walking test, TUG: Timed Up and Go, 6MWT: six-minute walking test; COP: center of pressure; COM: center of mass; AROM: active range of motion, GMFM: gross motor functional measurement; AP: anteroposterior, BWS: body-weight support; RFD: rate of force development. 
Table 3. Summary of training parameters and settings.

\begin{tabular}{|c|c|c|}
\hline Study & Training Parameters & Anti-Gravity Treadmill Settings \\
\hline $\begin{array}{l}\text { Kruz et al. } \\
\text { [27] }\end{array}$ & $\begin{array}{l}30 \text { min per session, } 2 \text { times per } \\
\text { week for } 6 \text { weeks }\end{array}$ & $\begin{array}{l}\text { BWS was set to } 40 \% \text { of body weight and gradually reduced to } 10 \% \text { by the end of } \\
\text { the intervention. The speed of the treadmill was initially set at } 90 \% \text { of the child's } \\
\text { over-ground walking speed and gradually increased. }\end{array}$ \\
\hline $\begin{array}{l}\text { Emara } \\
\text { et al. }[18]\end{array}$ & $\begin{array}{l}20 \text { min per session, } 3 \text { times per } \\
\text { week for } 12 \text { weeks }\end{array}$ & $\begin{array}{l}\text { BWS was set at } 30 \% \text { of the child's body weight. The speed of the tredmill was set } \\
\text { at } 75 \% \text { of over-ground speed and zero-degree inclination. }\end{array}$ \\
\hline $\begin{array}{l}\text { Emara } \\
\text { et al. }[19]\end{array}$ & $\begin{array}{l}20 \text { min per session, } 3 \text { times per } \\
\text { week for } 12 \text { weeks }\end{array}$ & $\begin{array}{l}\text { Comfortable treadmill speed was selected for all participants as } 75 \% \text { of their } \\
\text { comfortable speed during over-ground walking. The treadmill was set at } \\
\text { zero-degree inclination. }\end{array}$ \\
\hline $\begin{array}{l}\text { Birgani } \\
\text { et al. [29] }\end{array}$ & $\begin{array}{l}45 \text { min per session, } 3 \text { times per } \\
\text { week for } 8 \text { weeks. }\end{array}$ & $\begin{array}{l}\text { The training started with a } 50 \% \text { BWS and with a speed of } 1.5 \mathrm{~km} / \mathrm{h} \text {. Then, BWS } \\
\text { was gradually reduced and the speed was increased based on the subject's ability. }\end{array}$ \\
\hline $\begin{array}{l}\text { El-Shamy } \\
\text { [11] }\end{array}$ & $\begin{array}{l}20 \text { min per session added to } \\
1 \mathrm{~h} \text { of conventional therapy, } \\
3 \text { times per week for } 12 \text { weeks }\end{array}$ & $\begin{array}{l}\text { The treadmill was set at zero-degree inclination. Comfortable treadmill speed was } \\
\text { selected for all participants as } 75 \% \text { of their comfortable speed during over-ground } \\
\text { walking. Verbal commands were given to the children to maintain upright posture. }\end{array}$ \\
\hline $\begin{array}{l}\text { Rasooli } \\
\text { et al. [21] }\end{array}$ & $\begin{array}{l}45 \text { min per session, } 3 \text { times per } \\
\text { week for } 8 \text { weeks }\end{array}$ & $\begin{array}{l}\text { Each session, training started with } 50-70 \% \text { of body-weight support and } \\
0.7-1.5 \mathrm{~km} / \mathrm{h} \text { speed, depending on the patient's condition and tolerance. After } \\
\text { warmup, the body-weight support decreased and speed increased gradually } \\
\text { based on the therapist's evaluation of the patient's tolerance. }\end{array}$ \\
\hline $\begin{array}{l}\text { Lotfian } \\
\text { et al. [28] }\end{array}$ & $\begin{array}{l}45 \text { min per session, } 3 \text { times per } \\
\text { week for } 8 \text { weeks }\end{array}$ & $\begin{array}{l}\text { BWS was set at } 50 \% \text {, and the speed of the treadmill was started at about } 1 \mathrm{~m} / \mathrm{s} \text {. } \\
\text { After a } 3 \text { to } 4 \text { min warmup, the experienced trainer began to reduce the BWS and } \\
\text { increase the speed, changing them during training based on the patient's needs. }\end{array}$ \\
\hline $\begin{array}{c}\text { Azizi } \\
\text { et al. [21] }\end{array}$ & $\begin{array}{l}45 \text { min per session, } 3 \text { times per } \\
\text { week for } 8 \text { weeks }\end{array}$ & No information about anti-gravity treadmill settings. \\
\hline $\begin{array}{c}\text { Azizi } \\
\text { et al. }[30]\end{array}$ & $\begin{array}{l}45 \text { min per session, } 3 \text { times per } \\
\text { week for } 8 \text { weeks }\end{array}$ & $\begin{array}{l}\text { The inclination was set at } 0^{\circ} \text {. The speed and BWS of the treadmill were set to their } \\
\text { optimum level, at which patients had their best gait pattern. }\end{array}$ \\
\hline $\begin{array}{l}\text { Azizi et al. } \\
\text { [31] }\end{array}$ & $\begin{array}{l}45 \text { min per session, } 3 \text { times per } \\
\text { week for } 8 \text { weeks }\end{array}$ & $\begin{array}{l}\text { The inclination was set at } 0^{\circ} \text {. These parameters were set to the levels at which the } \\
\text { patient had the best walking pattern. The primary speed and BWS of each session } \\
\text { were dependent on the condition of the patient and were set to } 0.7-1.5 \mathrm{~km} / \mathrm{h} \text { and } \\
50-70 \% \text { of the normal weight, respectively. }\end{array}$ \\
\hline $\begin{array}{l}\text { Dadashi } \\
\text { et al. [23] }\end{array}$ & $\begin{array}{l}45 \text { min per session, } 3 \text { times per } \\
\text { week for } 8 \text { weeks }\end{array}$ & $\begin{array}{l}\text { At first, the BWS was set at } 50 \% \text { of the participant's weight, and the speed was set } \\
\text { at about } 1 \mathrm{~m} / \mathrm{s} \text {. As time passed, the speed increased, and the BWS } \\
\text { gradually decreased. }\end{array}$ \\
\hline $\begin{array}{l}\text { Azizi et al. } \\
\text { [24] }\end{array}$ & $\begin{array}{l}45 \text { min per session, } 3 \text { times per } \\
\text { week for } 8 \text { weeks }\end{array}$ & $\begin{array}{l}\text { The treadmill was set at zero-degree inclination, the initial speed was set to } \\
0.7 \mathrm{~km} / \mathrm{h} \text { and the body-weight support was selected according to gait patterns. }\end{array}$ \\
\hline $\begin{array}{l}\text { Lotfian } \\
\text { et al. [25] }\end{array}$ & $\begin{array}{l}45 \text { min per session, } 3 \text { times per } \\
\text { week for } 8 \text { weeks }\end{array}$ & $\begin{array}{l}\text { At the beginning of the training session, BWS was reduced by } 50 \% \text {, and the patient } \\
\text { was allowe to walk at a low speed to warm up. After } 4-5 \mathrm{~min} \text {, the BWS was } \\
\text { gradually decreased, while the speed was increased; the trainer adjusted these two } \\
\text { parameters to help the subject maintain a more accurate walking pattern. }\end{array}$ \\
\hline $\begin{array}{l}\text { Aras } \\
\text { et al. [20] }\end{array}$ & $\begin{array}{l}45 \text { min per session, } 5 \text { times per } \\
\text { week for } 4 \text { weeks }\end{array}$ & $\begin{array}{l}\text { BWS was started at } 60 \% \text { and gradually decreased to a level that prevented the } \\
\text { collapse of the knee in flexion during the stance phase. The treadmill speed was } \\
\text { initiated at the average walking speed according to the child's walking pattern, } \\
\text { weigh and endurance, then increased to the highest level tolerated. }\end{array}$ \\
\hline $\begin{array}{l}\text { Noroozi } \\
\text { et al. [33] }\end{array}$ & $\begin{array}{c}40 \text { min per session, } 3 \text { times per } \\
\text { week for } 8 \text { weeks }\end{array}$ & No information about anti-gravity treadmill settings. \\
\hline
\end{tabular}

\section{Discussion}

This scoping review summarized the available literature on the effects of anti-gravity treadmill training on lower-limb function and/or gait parameters in children with locomotor impairments. Overall, anti-gravity treadmill training has some positive effects on lower-limb function (i.e., strength and spasticity), balance and spatiotemporal gait parameters, mainly in children with CP. Given the small number of RCT studies and the quality of the included studies, the result of this review shows that investigation of the effects of 
anti-gravity treadmill training for the pediatric population with locomotor impairments is still at its early stage.

\subsection{Participant Characteristics}

The included studies investigated the effect of anti-gravity training on lower-limb function and/or gait parameters of children and adolescents with locomotor impairments. Most of the studies included children with cerebral palsy, a population with particularly severe and varied locomotor disorders [32]. The included studies reported positive effects of antigravity treadmill training regardless of age (age $=4-18$ years), and GMFCS level (ranging from I to IV) but do not allow a conclusion to be reached as to whether the training is more effective for a specific subpopulation. In general, over time, many factors can contribute to changes in motor function, including walking in individuals with neurologic diseases, including cerebral palsy, such as increased body weight, body-weight-to-strength ratio, contractures and spasticity. In addition, the various musculoskeletal problems observed during children's growth result in the intensification of primary disorders, particularly muscle weakness [32]. A lack of physical activity has also been identified as a potential contributing factor to muscle weakness in children with cerebral palsy [33]. Several studies included in the present review highlighted a positive effect of training on muscle strength $[18,27,28]$, spasticity [26], gross motor function [20] and walking capacities [11,20,22,24,25,27,28,31] in children with locomotor disorders. Hence, anti-gravity treadmill training could be viewed as a relevant modality to reduce the impact of growth on the functional capacity of children with neurological disorders.

\subsection{Anti-Gravity Training: Protocols and Settings}

Overall, anti-gravity treadmill training is based on the principles of motor learning and neuroplasticity through a mass-practice and task-specific intervention that aims to promote long-lasting neuromuscular adaptation [34]. However, optimal training frequency and duration for gait rehabilitation with the anti-gravity treadmill remains unknown due to the large variability between protocols in published studies. According to the recommendations of Verschuren et al. [35], longer interventions with progressive intensities (e.g., duration: 8-16 weeks; frequency: 2 or 4 sessions/week) may be needed to experience meaningful motor-function improvements in children with CP. Almost all the studies included in this review meet such recommendations.

Regarding the progression in training settings, it has been suggested that in order to get closer to normative gait patterns, very low speeds and high levels of BWS should be avoided when possible [36,37]. Depending on the study, initial BWS levels were adjusted between by 30 and $50 \%$. The treadmill speed was set to $0.7-1.5 \mathrm{~km} / \mathrm{h}$ and gradually increased. The effect of treadmill inclination is less obvious and still requires further investigation [38-40]. In this review, all studies had set this parameter to 0 deg. In general, the progression in these settings was poorly described. Moreover, no study reported individual data on setting progression. The disparate training schedules, combined with the lack of information about setting adjustments, limit our understanding of the impact of anti-gravity training on children with locomotor impairments and may preclude clinical reproduction of the proposed protocols [41].

\subsection{Effect of Training on Body Functions}

After anti-gravity treadmill training, a few studies reported an increase in lowerextremity strength (as measured in isometric or isokinetic mode) [18,27,28], a decrease in spasticity [26] and improvement in gross motor function [20]. These improvements are relevant and need to be confirmed by further studies with larger sample sizes. Spasticity and a lack of muscle strength play a key role in gait impairment, given the strong relationship between these parameters and walking ability in children with cerebral palsy [42-45]. Indeed, lower-limb muscle strength explains approximately $21-47.8 \%$ of ambulatory capacity in these children $[44,45]$. Strength and spasticity might be considered to determine 
whether a child with spastic cerebral palsy may benefit from an intervention to improve walking capacity.

\subsection{Effect of Anti-Gravity Training on Activity}

Compared to conventional therapy, five RCT studies [11,18,19,22,24] showed greater positive changes in balance and risk of falls after anti-gravity treadmill training. These findings are particularly important for children with cerebral palsy, as they must control the postural instability caused by the decoupling they often experience between the projection of their center of mass and center of pressure during gait [46]. As this physical impairment requires more energy for walking than in typically developing children [47], the acquisition of new locomotor capacities represents one of the primary objectives in these children.

Regarding gait parameters, several studies $[11,20,22,24,25,27,28,31]$ highlighted an improvement in spatiotemporal parameters after anti-gravity treadmill training. In his RCT, El-Shamy [11] showed that the group who benefited from anti-gravity treadmill training exhibited a grater improvement in gait parameters (i.e., walking speed, stride length, cadence and double-support time) compared to the control group. Despite the promising effects reported in this last study, the combination of anti-gravity training with a physical therapy program in the experimental groups limits the ability to isolate the contribution of the anti-gravity treadmill training alone. Recently, Aras et al. [20] investigated the effect of anti-gravity training (AlterG) in comparison to other modalities, including traditional BWS treadmill training and robotic-assisted treadmill training (Lokomat). Despite the presence of a trend, the authors did not observe a significant change in walking speed after the three training modalities. However, in the anti-gravity group, the increase in cadence, stride length, and stride time were statistically significant, while the increases in those parameters was not significant in the robotic and BWS groups. In these RCTs studies, the authors did not compare change scores to establish differences between groups but rather compared beginning and end values. In our opinion, this is a statistical limitation and might have influenced the results. Moreover, most of the selected outcome measures are known to be associated with walking speed $[11,20,22,24,25,27,28,31]$. Consequently, an increase in walking speed inherently induces an improvement in the majority of these outcomes. Unfortunately, the studies only concentrated on these spatiotemporal aspects and did not present other biomechanical parameters. However, to understand the different strategies used by children in gait production, it is important to enrich the overall biomechanical data by considering other factors, such as joint kinematics and kinetics, as well as EMG data.

In the pediatric population, the findings in the current literature on anti-gravity training modality show some promising benefits (i.e., balance and spatiotemporal parameters), specifically in children and adolescents with cerebral palsy. However, given the disparity of results and the variable quality of the studies conducted to date, more studies are needed to document the effectiveness of anti-gravity training compared to conventional approaches before clinical implementation can be recommended or not. In future studies, the implementation of personalized and well-designed protocols for anti-gravity training is needed to get a better understanding of how this modality could be applied in heterogenous populations of children with locomotor impairments. Moreover, additional information about the patient's gait performance during daily life, as a complement to laboratory-based assessments, could improve the understanding of the patient's overall gait difficulties, enhancing clinical care.

There are some limitations to this review that need to be acknowledged. First, the major limitation of this review concerns restrictions of publication language and type of publication; therefore, publication bias might be present. Second, the heterogeneity in population characteristics (e.g., age, GMFCS levels) limits the possibility of generalizing results.

\section{Conclusions}

Our analysis of the literature showed a low level of evidence for employing antigravity treadmill training to improve gait ability in children with locomotor impairments. 
Well-designed, high-quality clinical trials that complement clinical data with objective, quantitative gait data are needed to provide more detailed information on the potential effects of anti-gravity training in general, as well as on its specific impact on gait movement patterns. Finally, studies are needed to investigate the differences between a lower-body positive-pressure-based and a harness-based body-weight-supported system and their specific influence on gait parameters.

Supplementary Materials: The following are available online at https:/ / www.mdpi.com/article/10.3 390/app12010323/s1, Table S1: Search terms.

Author Contributions: Y.C. developed the search strategy and the assessment framework for this review, which have been validated by a science librarian. C.M., Y.C. and L.G.-P. screened the search hits for eligibility and the quality of rated studies. Y.C. extracted and synthesized the relevant data and wrote the first draft of the manuscript. C.M. and L.B. performed a major revision of the manuscript. All authors have read and agreed to the published version of the manuscript.

Funding: This research received no external funding.

Institutional Review Board Statement: Not applicable.

Informed Consent Statement: Not applicable.

Data Availability Statement: Data sharing is not applicable to this article as no datasets were generated or analyzed during the current study.

Acknowledgments: Y.C. receives a fellowship from Fonds de recherche du Québec-Santé (FRQS), and L.G.-P. from Centre interdisciplinaire de recherche en réadaptation et intégration sociale (Cirris). C.M. is Emerita Research Scholar of FRQS and the Universite Laval Cerebral Palsy Research Chair. The authors thank Martine Gagnon (a science librarian at Laval University) for her guidance and advice during the implementation of the research strategy.

Conflicts of Interest: The authors declare that they have no competing interests and there are no competing financial interests to declare in relation to this manuscript.

\section{References}

1. Cherni, Y.; Laforte, A.P.; Parent, A.; Marois, P.; Begon, M.; Ballaz, L. Lower limb extension is improved in fast walking condition in children who walk in crouch gait. Disabil. Rehabilitation 2019, 41, 3210-3215. [CrossRef] [PubMed]

2. Duffy, C.M.; Hill, A.E.; Cosgrove, A.P.; Carry, I.S.; Graham, H.K. Energy Consumption in children with spina bifida and cerebral palsy: A comparative study. Dev. Med. Child Neurol. 2008, 38, 238-243. [CrossRef] [PubMed]

3. Kim, C.J.; Son, S.M. Comparison of Spatiotemporal Gait Parameters between Children with Normal Development and Children with Diplegic Cerebral Palsy. J. Phys. Ther. Sci. 2014, 26, 1317-1319. [CrossRef] [PubMed]

4. Pirpiris, M.; Gates, P.E.; McCarthy, J.J.; D’Astous, J.; Tylkowksi, C.; Sanders, J.O.; Dorey, F.J.; Ostendorff, S.; Robles, G.; Caron, C.; et al. Function and well-being in ambulatory children with cerebral palsy. J. Pediatr. Orthop. 2006, 26, 119-124. [CrossRef] [PubMed]

5. Marino, F.R.; Lessard, D.M.; Saczynski, J.S.; McManus, D.D.; Silverman-Lloyd, L.G.; Benson, C.M.; Blaha, M.J.; Waring, M.E. Gait speed and mood, cognition, and quality of life in older adults with atrial fibrillation. J. Am. Hear. Assoc. 2019,8 , e013212. [CrossRef] [PubMed]

6. Zwicker, J.G.; Mayson, T.A. Effectiveness of treadmill training in children with motor impairments: An overview of systematic reviews. Pediatr. Phys. Ther. 2010, 22, 361-377. [CrossRef]

7. Novak, I.; McIntyre, S.; Morgan, C.; Campbell, L.; Dark, L.; Morton, N.; Stumbles, E.; Wilson, S.-A.; Goldsmith, S. A systematic review of interventions for children with cerebral palsy: State of the evidence. Dev. Med. Child Neurol. 2013, 55, 885-910. [CrossRef]

8. Cutuk, A.; Groppo, E.R.; Quigley, E.J.; White, K.W.; Pedowitz, R.A.; Hargens, A.R. Ambulation in simulated fractional gravity using lower body positive pressure: Cardiovascular safety and gait analyses. J. Appl. Physiol. 2006, 101, 771-777. [CrossRef]

9. Patil, S.; Steklov, N.; Bugbee, W.D.; Goldberg, T.; Colwell, C.W.; D'Lima, D.D. Anti-gravity treadmills are effective in reducing knee forces. J. Orthop. Res. 2012, 31, 672-679. [CrossRef]

10. de Heer, H.D.; Kline, J.R.; Charley, B. Anti-Gravity Treadmill Training for Prevention and Rehabilitation of Running Injuries. In Clinical Care of the Runner; Harrast, M.A., Ed.; Elsevier BV: Amsterdam, The Netherlands, 2020; pp. 113-130.

11. El-Shamy, S. Effects of Antigravity Treadmill training on gait, balance, and fall risk in children with diplegic cerebral palsy. Am. J. Phys. Med. Rehab. 2017, 96, 809-815. [CrossRef]

12. Draovitch, P.; Maschi, R.A.; Hettler, J. Return to sport following hip injury. Curr. Rev. Musculoskelet. Med. 2012, 5, 9-14. [CrossRef] 
13. Peeler, J.; Ripat, J. The effect of low-load exercise on joint pain, function, and activities of daily living in patients with knee osteoarthritis. Knee 2018, 25, 135-145. [CrossRef] [PubMed]

14. Tricco, A.C.; Lillie, E.; Zarin, W.; O’Brien, K.K.; Colquhoun, H.; Levac, D.; Moher, D.; Peters, M.D.; Horsley, T.; Weeks, L.; et al. PRISMA Extension for Scoping Reviews (PRISMA-ScR): Checklist and Explanation. Ann Intern. Med. 2018, 169, 467-473. [CrossRef] [PubMed]

15. Peters, M.D.; Godfrey, C.M.; Khalil, H.; McInerney, P.; Parker, D.; Soares, C.B. Guidance for conducting systematic scoping reviews. Int. J. Evid. Based Health 2015, 13, 141-146. [CrossRef] [PubMed]

16. Maher, C.G.; Sherrington, C.; Herbert, R.D.; Moseley, A.M.; Elkins, M. Reliability of the PEDro Scale for Rating Quality of Randomized Controlled Trials. Phys. Ther. 2003, 83, 713-721. [CrossRef]

17. World Health Organization. International Classification of Functioning, Disability and Health: Children and Youth Version: ICF-CY; World Health Organization: Geneva, Switzerland, 2007. Available online: https://apps.who.int/iris/handle/10665/43737 (accessed on 29 November 2021).

18. Emara, H. The Role of Antigravity Treadmill in Haemophilic Children Aged 8 to 11 Years with Unilateral Knee Haemarthrosis without Radiological Involvement. Br. J. Med. Med. Res. 2015, 10, 1-10. [CrossRef]

19. Emara, H.A.M.A.H. Effect of a new physical therapy concept on dynamic balance in children with spastic diplegic cerebral palsy. Egypt. J. Med. Hum. Genet. 2015, 16, 77-83. [CrossRef]

20. Aras, B.; Yaşar, E.; Kesikburun, S.; Türker, D.; Tok, F.; Yılmaz, B. Comparison of the effectiveness of partial body weight-supported treadmill exercises, robotic-assisted treadmill exercises, and anti-gravity treadmill exercises in spastic cerebral palsy. Turk. J. Phys. Med. Rehabil. 2019, 65, 361-370. [CrossRef]

21. Rasooli, A.H.; Birgani, P.M.; Azizi, S.; Shahrokhi, A.; Mirbagheri, M.M. Therapeutic effects of an anti-gravity locomotor training (AlterG) on postural balance and cerebellum structure in children with Cerebral Palsy. In Proceedings of the 2017 International Conference on Rehabilitation Robotics (ICORR), London, UK, 17-20 July 2017; Volume 2017, pp. 101-105. [CrossRef]

22. Azizi, S.; Marzbani, H.; Raminfard, S.; Birgani, P.; Rasooli, A.; Mirbagheri, M.M. The impact of an anti-gravity treadmill (AlterG) training on walking capacity and corticospinal tract structure in children with cerebral palsy. In Proceedings of the 2017 39th Annual International Conference of the IEEE Engineering in Medicine and Biology Society (EMBC), Jeju, Korea, 11-15 July 2017; pp. 1150-1153. [CrossRef]

23. Dadashi, F.; Kharazi, M.R.; Lotfian, M.; Shahroki, A.; Mirbagheri, A.; Mirbagheri, M.M. The Effects of Lower Body Positive Pressure Treadmill Training on Dynamic Balance of Children with Cerebral Palsy. In Proceedings of the 2018 40th Annual International Conference of the IEEE Engineering in Medicine and Biology Society (EMBC), Honolulu, HI, USA, 18-21 July 2018; Volume 2018, pp. 2487-2490. [CrossRef]

24. Azizi, S.; Birgani, P.M.; Irani, A.; Shahrokhi, A.; Nourian, R.; Mirbagheri, M. Impact of anti-gravity locomotion (AlterG) training on structure and function of corticospinal tract and gait in children with cerebral palsy. In Proceedings of the 2019 41st Annual International Conference of the IEEE Engineering in Medicine and Biology Society (EMBC), Berlin, Germany, 23-27 July 2019; Volume 2019, pp. 126-129. [CrossRef]

25. Lotfian, M.; Dadashi, F.; Rafieenazari, Z.; Shahroki, A.; Rasteh, M.; Molavi, M.; Mirbagheri, A.; Mirbagheri, M. The Effects of Anti-gravity Treadmill Training on Gait Characteristics in Children with Cerebral Palsy. In Proceedings of the 2019 41st Annual International Conference of the IEEE Engineering in Medicine and Biology Society (EMBC), Berlin, Germany, 23-27 July 2019; Volume 2019, pp. 5256-5259. [CrossRef]

26. Noroozi, S.; Mehrabi, R.; Lotfian, M.; Nooshiravan, F.; Shahroki, A.; Irani, A.; Mirbagheri, M.M. Therapeutic Effects of an Anti-Gravity Treadmill (AlterG) Training on Neuromuscular Abnormalities Associated with Spasticity in Children with Cerebral Palsy*. In Proceedings of the 2020 42nd Annual International Conference of the IEEE Engineering in Medicine \& Biology Society (EMBC), Montreal, QC, Canada, 20-24 July 2020; Volume 2020, pp. 3856-3859. [CrossRef]

27. Kurz, M.J.; Corr, B.; Stuberg, W.; Volkman, K.; Smith, N. Evaluation of Lower Body Positive Pressure Supported Treadmill Training for Children with Cerebral Palsy. Pediatr. Phys. Ther. 2011, 23, 232-239. [CrossRef]

28. Lotfian, M.; Kharazi, M.R.; Mirbagheri, A.; Dadashi, F.; Nourian, R.; Mirbagheri, M.M. Therapeutic effects of an anti-gravity treadmill (AlterG) training on gait and lower limbs kinematics and kinetics in children with cerebral palsy. In Proceedings of the 2017 International Conference on Rehabilitation Robotics (ICORR), London, UK, 17-20 July 2017; Volume 2017, pp. 170-174. [CrossRef]

29. Birgani, P.M.; Ashtiyani, M.; Rasooli, A.; Shahrokhnia, M.; Shahrokhi, A.; Mirbagheri, M. Can an anti-gravity treadmill improve stability of children with cerebral palsy? In Proceedings of the 2016 38th Annual International Conference of the IEEE Engineering in Medicine and Biology Society (EMBC), Orlando, FL, USA, 16-20 August 2016; Volume 2016, pp. 5465-5468. [CrossRef]

30. Azizi, S.; Birgani, P.M.; Marzbani, H.; Nourian, R.; Kohanpour, M.; Mirbagheri, M.M. Assessment of neuroplasticity of corticospinal tract induced by antigravity treadmill (AlterG) in cerebral palsy children. In Proceedings of the 2018 40th Annual International Conference of the IEEE Engineering in Medicine and Biology Society (EMBC), Honolulu, HI, USA, 18-21 July 2018; Volume 2018, pp. 2495-2498. [CrossRef]

31. Azizi, S.; Rasooli, A.H.; Soleimani, M.; Irani, A.; Shahrokhi, A.; Mirbagheri, M.M. The impact of AlterG training on balance and structure of vestibulospinal tract in cerebral palsy children. In Proceedings of the 2018 40th Annual International Conference of the IEEE Engineering in Medicine and Biology Society (EMBC), Honolulu, HI, USA, 18-22 July 2018; pp. 2499-2502. [CrossRef] 
32. E Hanna, S.; Bartlett, D.J.; Rivard, L.M.; Russell, D.J. Reference Curves for the Gross Motor Function Measure: Percentiles for Clinical Description and Tracking Over Time Among Children with Cerebral Palsy. Phys. Ther. 2008, 88, 596-607. [CrossRef]

33. Fowler, E.G.; Kolobe, T.H.; Damiano, D.L.; E Thorpe, D.; Morgan, D.W.; Brunstrom, J.E.; Coster, W.J.; Henderson, R.C.; Pitetti, K.H.; Rimmer, J.H.; et al. Stevenson, Section on Pediatrics Research Summit Participants, Section on Pediatrics Research Committee Task Force, Promotion of physical fitness and prevention of secondary conditions for children with cerebral palsy: Section on pediatrics research summit proceedings. Phys. Ther. 2007, 87, 1495-1510. [CrossRef]

34. Kleim, J.A.; Jonest, T. Principles of Experience-Dependent Neural Plasticity: Implications for Rehabilitation after Brain Damage. J. Speech Lang. Heart Res. 2008, 51, S225-S239. [CrossRef]

35. Verschuren, O.; Peterson, M.D.; Balemans, A.C.; Hurvitz, E.A. Exercise and physical activity recommendations for people with cerebral palsy. Dev. Med. Child Neurol. 2016, 58, 798-808. [CrossRef] [PubMed]

36. Van Kammen, K.; Boonstra, A.; Reinders-Messelink, H.; Otter, R.D. The Combined Effects of Body Weight Support and Gait Speed on Gait Related Muscle Activity: A Comparison between Walking in the Lokomat Exoskeleton and Regular Treadmill Walking. PLoS ONE 2014, 9, e107323. [CrossRef]

37. Cherni, Y.; Hajizadeh, M.; Maso, F.D.; Turpin, N.A. Effects of body weight support and guidance force settings on muscle synergy during Lokomat walking. Eur. J. Appl. Physiol. 2021, 121, 2967-2980. [CrossRef]

38. Werner, C.; Lindquist, A.R.; Bardeleben, A.; Hesse, S. The Influence of Treadmill Inclination on the Gait of Ambulatory Hemiparetic Subjects. Neurorehabilit. Neural Repair 2007, 21, 76-80. [CrossRef] [PubMed]

39. Ma, Y.; Liang, Y.; Kang, X.; Shao, M.; Siemelink, L.; Zhang, Y. Gait Characteristics of Children with Spastic Cerebral Palsy during Inclined Treadmill Walking under a Virtual Reality Environment. Appl. Bionics Biomech. 2019, 2019. [CrossRef] [PubMed]

40. Willerslev-Olsen, M.; Petersen, T.H.; Farmer, S.; Nielsen, J.B. Gait training facilitates central drive to ankle dorsiflexors in children with cerebral palsy. Brain 2015, 138, 589-603. [CrossRef] [PubMed]

41. Warken, B.; Graser, J.V.; Ulrich, T.; Borggraefe, I.; Heinen, F.; Meyer-Heim, A.; van Hedel, H.J.A.; Schroeder, A.S.; Aurich, T. Practical Recommendations for Robot-Assisted Treadmill Therapy (Lokomat) in Children with Cerebral Palsy: Indications, Goal Setting, and Clinical Implementation within the WHO-ICF Framework. Neuropediatrics 2015, 46, 248-260. [CrossRef]

42. Ross, S.A.; Engsberg, J.R. Relationships between spasticity, strength, gait, and the GMFM-66 in persons with spastic diplegia cerebral palsy. Arch. Phys. Med. Rehab. 2007, 88, 1114-1120. [CrossRef]

43. Bar-On, L.; Molenaers, G.; Aertbeliën, E.; Monari, D.; Feys, H.; Desloovere, K. The relation between spasticity and muscle behavior during the swing phase of gait in children with cerebral palsy. Res. Dev. Disabil. 2014, 35, 3354-3364. [CrossRef]

44. Dallmeijer, A.J.; Rameckers, E.A.; Houdijk, H.; de Groot, S.; Scholtes, V.A.; Becher, J.G. Isometric muscle strength and mobility capacity in children with cerebral palsy. Disabil. Rehab. 2017, 39, 135-142. [CrossRef]

45. Ferland, C.; Lepage, C.; Moffet, H.; Maltais, D.B. Relationships Between Lower Limb Muscle Strength and Locomotor Capacity in Children and Adolescents with Cerebral Palsy Who Walk Independently. Phys. Occup. Ther. Pediatr. 2011, 32, 320-332. [CrossRef] [PubMed]

46. Wallard, L.; Dietrich, G.; Kerlirzin, Y.; Bredin, J. Balance control in gait children with cerebral palsy. Gait Posture 2014, 40 , 43-47. [CrossRef] [PubMed]

47. Campbell, J.; Ball, J. Energetics of walking in cerebral palsy. Orthop. Clin. N. Am. 1978, 9, 374-377. 